\title{
MODELING BATTERY LIVE CYCLE DATA WITH TEMPORAL SERIES: A NETWORK THEORY APPROACH
}

\author{
Roberto C Costa ${ }^{a}$, Hernane B. B. Pereira ${ }^{b}$, Thiago Murari ${ }^{a, b}$ Marcelo Moret ${ }^{b}$ \\ a Product Development, Ford Motor Company, Brazil, \\ b Programa de Modelagem Computacional e Tecnologia Industrial, Centro \\ Universitário Senai Cimatec, Brazil,
}

\begin{abstract}
This paper presents an application of conceptual map and network theory in a link with the lead-acid battery live cycle model applied in automobiles. The key objective is to understand the relationship between battery and vehicle interfaces to generate battery data, allowing a statistical understanding of battery live cycle versus a benchmark network generated by same theme abstracts. The firsts step was to create a conceptual map from vehicle battery system, including vehicle data collection and proposed statistical studies. The second phase was focused in generate the network and its statistical studies based on the raw data from conceptual map. A small word graphs were obtained together with $75 \%$ of concept match between top nodes concept from actual and abstracts graphs.
\end{abstract}

Keywords: Lead-Acid Battery; State of Health; Vehicle; Network;

\section{MODELAGEM DE DADOS SOBRE CICLO DE VIDA DE BATERIAS PARA SÉRIES TEMPORAIS: NO CONTEXTO DE TEORIA DE REDES}

Resumo: Este artigo apresenta uma aplicação do mapa conceitual e da teoria de redes relacionando com uma proposta de modelagem sobre ciclo de vida de baterias. O objetivo principal é delinear as interfaces da bateria e do veículo para gerar dados, permitindo um entendimento estatístico do ciclo de vida da bateria comparado a uma rede de benchmark gerada a partir de resumos de artigos sobre o mesmo tema. $O$ primeiro passo foi criar um mapa conceitual do sistema de bateria do veículo, incluindo a coleta de dados e estudos estatísticos propostos. A segunda fase foi focada em gerar a rede e seus estudos estatísticos com base nos dados brutos do mapa conceitual. Conclui-se em redes de mundo pequenos com uma sinergia cognitiva de $75 \%$ dos conceitos entre os top vértices das redes gerada e de resumo.

Palavras-chave: Bateria de Chumbo-Ácido; Estado de Saúde; Veículo; Redes; 


\section{INTRODUCTION}

Considering the importance of vehicle inside people transportation, the leadacid battery presents the basis to crank the internal combustion engine allowing this transportation [1]. Also, it's common to see vehicle batteries achieving its end of life in a moment that battery is not able to crank the engine anymore, causing a dissatisfaction to the vehicle drivers.

In this paper, we present a link between semantic network application and prediction of lead acid battery end-of-life, using temporal series inside automotive context. The main goal is to evaluate a generated conceptual map from battery life cycle versus a benchmark network based on the scientific research inside same topic.

Considering this scope and exposing a high-level view of this topic, the battery prediction main objective intent to collect the internal ECUs (Electronic Control Units) parameter and identify those with higher impact inside battery life time. The prediction desired outcome should be achieved when a correlation can indicate the battery health condition prior completely dead (not able to crank the engine).

The semantic network then is used to make a preliminary assessment of cognitive knowledge from presented theme, including a high-level view of battery usage life cycle, crossing all phases since battery production, usage in the vehicle, monitoring the information flow inside vehicle ECUs and considering statistical analysis to be executed. The benchmark network used is defined by a significant bibliography of studies abstracts from same theme since 2004 with several limits defined in the methodology section.

This article is structured inside 4 sections. The first one is the introduction, presenting preliminary information and a view of background studies available in the academy, presenting a correlated study about this topic; second section consists in detail the methodology used to generate the conceptual map and graphs; third section discuss the results of generated graphs versus random graph with same size; the last phase presents a conclusion of this workstream to support battery prediction view.

\subsection{Correlated Studies}

Pereira et al. presented a method using semantic networks to analyze the efficiency of diffusion of knowledge, evaluation several scientific journals. They concluded that their method can be used as a tool to study semantic networks with contribution to support authors/researcher during selection of journal to submit the results [2].

Inside preliminary studies about predicting battery life time in automotive context, there are several workstreams published to define methods and models of battery as presented in next paragraphs. The keywords normally used for battery end of life studies and used here in this research are: "Lead-Acid Battery", "SoH - State of Health" and "Automotive/Vehicle". These keywords were the base to form the benchmark dataset, also adding some inclusion/exclusion criteria covered in the methodology section to complete this set of articles. Below few available examples of papers included in the benchmark research, showing direct link with predict battery end of life:

Okoshi et al. presented a method based on a relationship between SoC (State of Charge) and DCR (Direct Current Resistance) aim a better SoC estimative for lead- 
acid batteries, being capable to achieve precision levels of $+/-5 \%$, improving the previous standards of SoC [3].

Zhang et al. brought an interesting contribution to academy community with an estimative method for SoH (State of Health) of lead acid batteries. They proposed an estimative method of $\mathrm{SoH}$ based on battery internal resistance and the voltage drop during a vehicle crank, causing a better diagnostic versus the conventional methods based on resistance. Interesting point, also mentioned by Zhang et al., is related with suggestion of link future works studies with statistical methods for this topic [4].

Also bringing to recent publications, Piłatowicz et al. presented an electrical model based in the Butler-Volmer equation. This study is focused on SoC and SoH estimation based on a range of current discharge range, $\mathrm{SoC}$ and temperature. The conclusion presents an algorithm for a dynamic estimative, being capable to predict the voltage drop with high precision even inside different operational conditions [5].

\section{METHODOLOGY}

\subsection{Network Creation}

In order to create this paper, the following software have been used: CmapTools Version 6.04 which is responsible to support creation of conceptual map; criar.NET version 1.1 [6], used to create file inside format Pajek (.NET); Gephi version 0.9.2 [7], used to execute statistical calculation and analyses in the network theory; and RStudio to execute calculations of some network properties with the package brainGraph [8].

The method applied started with a sequence of conceptual map creation indicating the lead-acid battery as the central point, including important aspects of battery internal design, not going too deep inside battery process related with battery production (out of scope). In the sequence, the main battery interfaces in the vehicle were raised, including steps needed to acquire battery parameter during vehicle usage (available sensors and key modules). The final portion was related with data acquisition from vehicle, data mining and processing, up to statistical studies and results. The CmapTools was used to consolidate all data generated here, creating all semantic links and allowing to export a structured file to be used in the next step.

After conceptual map completion, the network file type was created using the criar.NET software [6]. In this step, the CmapTools structure file was included as input file, the "TAB" was selected as separator and "1-mode" network was requested to be created, considering the "concepts" from conceptual map as network nodes. The software output is a file with extension ".NET" that can be used in the Gephi and RStudio.

Inside Gephi software [7], a non-directional network was created without edges merge. The following statistical calculations were executed: "Average Degree", "Network Diameter", "Graph Density", "Connected Components", "Avg. Clustering Coefficient" and "Avg. Path Length". Towards to improve the nodes and edges visualization, the nodes received a tuning for its size and color, requested a layout adjust using "Force Atlas 2", checking the option of "Dissuade Hubs" and "Prevent Overlap". A network picture and the network statistical calculation were considered as the output from this last step.

The RStudio with brainGraph package [8] is used to calculate additional network calculation for "Transitivity", "Global Efficiency", "Local Efficiency". 


\subsection{Benchmark Network Development}

The benchmark network creation considered this research command: (SoH OR "State of Health") AND "Lead-Acid Battery" AND (automotive OR vehicle). This research was mainly executed in the ScienceDirect and IEEE database. Refined from years to be included: 2004 up to 2021; article type: Research articles or Book chapters. Also removed direct mention with: lithium-ion, photovoltaic, stop-go, nickel metal hydride, Electric Vehicle (BEV), $2^{\text {nd }}$ life usage, Stationery usage. A benchmark of 22 papers were included.

These 22 papers abstracts were considered as the benchmark network. Allowing a better comparison, few additional rules were included, following similar method adopt by Pereira et al. [2]. A control dictionary was raised to support adjustments in the abstract, combining and removing words to make the graph as similar as possible to the conceptual map graph, as example combine words "state of health" to become "stateofhealth" and remove link verbs as "show", "apply", "approach", "moreover".

\section{RESULTS AND DISCUSSION}

The conceptual map presents an interdependence from battery to the remaining peripherical components, as can be observed in the Figure 1. The data set acquired by the battery sensor allows the statistical studies to be executed, as example calculate $\mathrm{SoH}$, supporting the main objective of battery life cycle studies which is modeling the battery end of life based on temporal series.

Figure 1. Conceptual map raised during study.

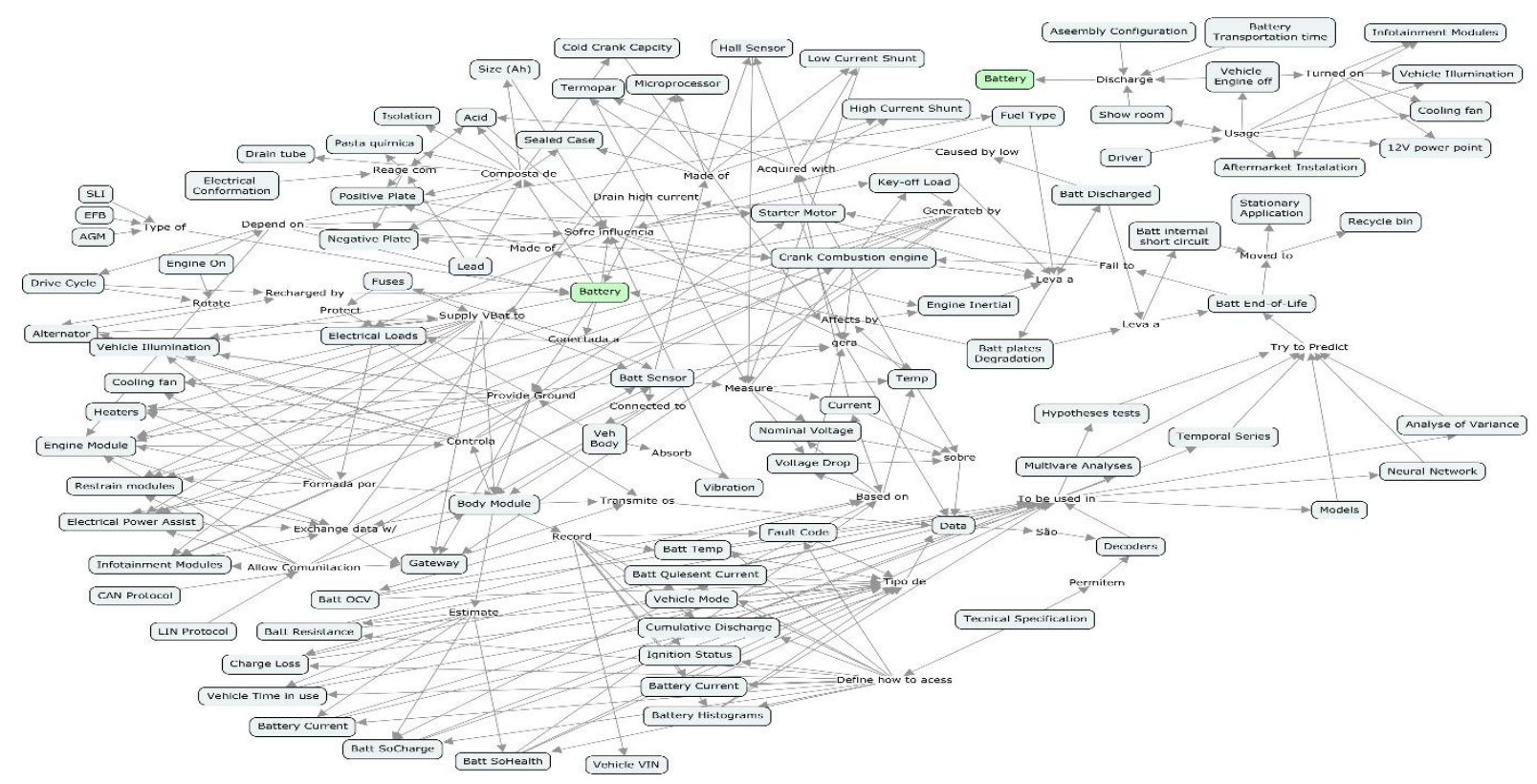

Once the conceptual map information migrates to a network and complete the adjustments, an undirected graph with 80 nodes and 381 edges was generated as showed in the Figure 2. In a first observation, it's possible to detect 4 main hubs in the graph: Battery, Batt Sensor, Body Module and Data. Correlating with battery end-oflive prediction, these main hubs represent, the component that suffer degradation 
(Battery), the sensor to acquired battery parameters online (Batt Sensor), the module responsible (Body Module) to monitor, record and estimate battery data (Data), prior proper statistical studies inside temporal series outside the car.

Figure 2. Graph generated based on conceptual map.

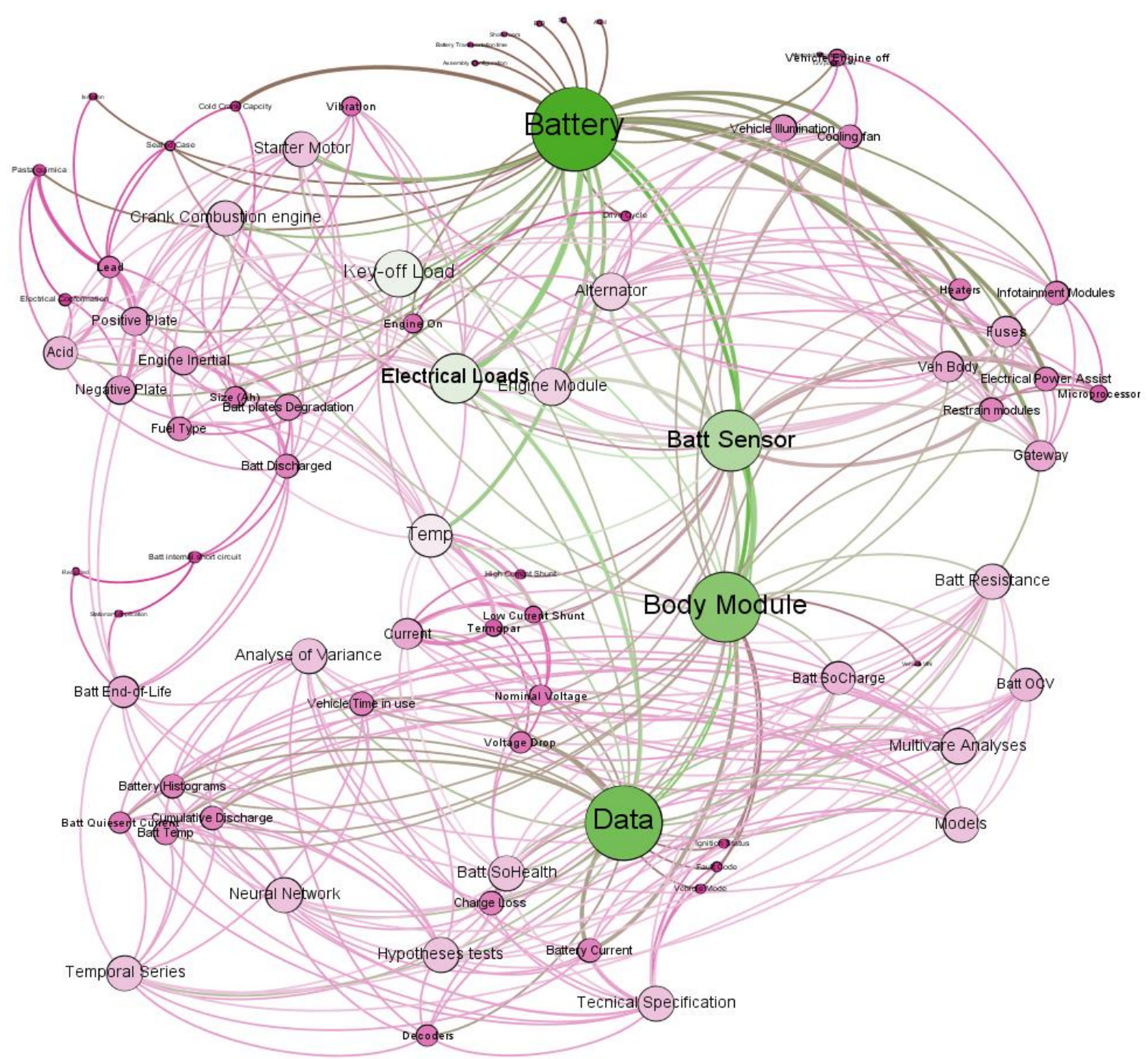

Going deeply inside statistical calculation following network theory, the Table 1 presents a result summary of graph calculated in the Gephi and RStudio for Actual graph (based on conceptual map) and also to Abstracts graph. Related with actual graph, the Average Degree allow understanding an average of 10.5 edges moving out of each node. This information supports identification of main hubs in the graph, this means the nodes with highest number of edges. The Network Diameter was 5, which means the largest distance between two nodes in this graph. The Graph Density was $13.3 \%$, which indicates a small quantity of connections between nodes, but reflects the cognitive understanding of battery information cascade flow during a normal usage. The Average Clustering Coefficient was 0.347 and the Average Path Length was 2.563. The information of abstract network can be visualized also in the Table 1.

Random graphs were created to allow a network comparison for both graphs (actual and abstracts). These random graphs were generated based on Erdős and Rényi [9] configuration model with a graph $G(n, p)$ where $p=<k>/(n-1)$, this means for actual graph $n=80$ and $p=10.5 / 79$ and for abstract graph $n=783$ and $p=25.497$ / 782. These random graphs calculations can also be observed in table 1 . 
Table 1. Statistical results from actual, abstracts and random graphs.

\begin{tabular}{|c|c|c|c|c|c|}
\hline Symbol & Statistical studies & $\begin{array}{l}\text { Actual } \\
\text { Graph }\end{array}$ & $\begin{array}{c}\text { Random Graph } \\
\text { (Based on } \\
\text { Actual) }\end{array}$ & $\begin{array}{c}\text { Abstract } \\
\text { Graph }\end{array}$ & $\begin{array}{c}\text { Random Graph } \\
\text { (Based on } \\
\text { Abstracts) }\end{array}$ \\
\hline$n=|V|$ & Total Nodes & 80 & 80 & 783 & 783 \\
\hline$m=|E|$ & Total Edges & 420 & 373 & 9982 & 9902 \\
\hline$<k>$ & Average Degree & 10.5 & 4.662 & 25.497 & 12.646 \\
\hline$D$ & Network Diameter & 5 & 4 & 12 & 3 \\
\hline$\Delta$ & Graph Density & 0.133 & 0.118 & 0.033 & 0.032 \\
\hline Cws & Avg. Clustering Coefficient & 0.342 & 0.121 & 0.801 & 0.032 \\
\hline$L$ & Avg. Path Length & 2.441 & 2.18 & 2.232 & 2.395 \\
\hline$C$ & Transitivity & 0.281 & 0.118 & 0.255 & 0.032 \\
\hline Eglobal & Global Efficiency & 0.477 & 0.509 & 0.467 & 0.445 \\
\hline Elocal & Local Efficiency & 0.492 & - & 0.385 & - \\
\hline
\end{tabular}

The actual and abstract graphs have a higher Average Clustering Coefficient $(C)$ then their respective equivalent random graphs, thus both present a small-world network phenomenon.

Additional cognitive verification was executed based on the similarity of concepts from top notes, rank based on node degree from actual and abstract network, as showed on Table 2. Starting with top10, several synergies can be observed as highlighted with same color level for 3 group of concepts. Increasing to top20, the number of synergies increases to 7 group of concepts. This comparison confirms key point of studies being published versus the conceptual map key relationship being evaluated. 15 out of 20 concepts have a correlation of meaning within top 20 abstract nodes.

Table 2. Top nodes degree comparison, between actual and abstract graphs.

\begin{tabular}{|c|c|c|c|}
\hline \multicolumn{3}{|c|}{ Top 10 Comparison (Based on Degree) } \\
\hline \multicolumn{2}{|c|}{ Actual Graph } & \multicolumn{2}{c|}{ Abstracts Graph } \\
\hline Battery & 35 & battery & 556 \\
\hline Data & 31 & stateofhealth & 272 \\
\hline Body Module & 29 & vehicle & 221 \\
\hline Batt Sensor & 25 & leadacid & 204 \\
\hline Electrical Loads & 20 & stateofcharge & 199 \\
\hline Key-off Load & 19 & system & 194 \\
\hline Temp & 17 & base & 186 \\
\hline Engine Module & 15 & method & 179 \\
\hline Alternator & 15 & model & 167 \\
\hline Batt SoHealth & 14 & time & 164 \\
\hline
\end{tabular}

\begin{tabular}{|c|c|c|c|}
\hline \multicolumn{4}{|c|}{ Top 20 Comparison (Based on Degree) } \\
\hline \multicolumn{2}{|c|}{ Actual Graph } & \multicolumn{2}{c|}{ Abstracts Graph } \\
\hline Battery & 35 & battery & 556 \\
\hline Data & 31 & stateofhealth & 272 \\
\hline Body Module & 29 & vehicle & 221 \\
\hline Batt Sensor & 25 & leadacid & 204 \\
\hline Electrical Loads & 20 & stateofcharge & 199 \\
\hline Key-off Load & 19 & system & 194 \\
\hline Temp & 17 & base & 186 \\
\hline Engine Module & 15 & method & 179 \\
\hline Alternator & 15 & model & 167 \\
\hline Batt SoHealth & 14 & time & 164 \\
\hline Multivare Analyses & 14 & current & 157 \\
\hline Crank Combustion engine & 14 & monitor & 150 \\
\hline Temporal Series & 14 & state & 131 \\
\hline Neural Network & 14 & present & 128 \\
\hline Tecnical Specification & 14 & real & 125 \\
\hline Hypotheses tests & 14 & age & 125 \\
\hline Models & 14 & algorithm & 123 \\
\hline Analyse of Variance & 14 & power & 122 \\
\hline Starter Motor & 14 & voltage & 117 \\
\hline Batt Resistance & 14 & storage & 114 \\
\hline
\end{tabular}


Following the method of generate a conceptual map, then generate a bibliographic study, compare both results versus random graphs and also correlate top nodes meaning, give us a good confidence level at a starting point study inside the theme of predict battery end of life.

\section{CONCLUSION}

The usage of conceptual map supports the consolidated understanding, presenting several links with concepts needed to model the selected theme, with a high-level view and a clear boundary of theme limits and a preliminary detail of all important concepts.

The network properties calculation allowed to identify a small-world phenomenon inside the actual and abstract graphs, as higher average clustering coefficient and similar average path length for both networks were calculated versus equivalent random graphs.

The 4 main hubs found in the actual network ("Battery", "Batt Sensor", "Body Module" and "Data") represented the main pillars to proceed with the battery end-oflife prediction. Also, fifteen out of 20 top degree concepts from actual graph can be linked with top 20 abstract top degree nodes, showing a good cognitive relationship between both networks.

A proposal of future research work to improve the battery prediction workstream is link this subject with Object Oriented Model using UML, as those methodologies could be applied inside data de-codification phase after data being collect from vehicle ECUs, before executing all statistical studies. Another opportunity would be get a detailed deep dive inside data, providing an overall relationship between each data and vehicle variation.

\section{Acknowledgments}

The authors would like to thank Ford Motor Company and Electrical \& Electronics Systems Engineering (EESE) manager, Carlo Hess, the opportunity of publishing our work, to my master advisors, Marcelo Moret, Thiago Murari and Hernane Pereira, regarding their support and dedication.

Appreciation and thanks are extended to all members of the Electrical \& Electronics Systems Engineering (EESE) and Vehicle Verification (VEV) - FSA team.

\section{REFERENCES}

${ }^{1}$ CHUMCHAL, C.; KURZWEIL, D. Lead-acid battery operation in micro-hybrid and electrified vehicles. In: Lead-Acid Batteries for Future Automobiles. Elsevier, 2017. p. 395-414.

2 PEREIRA, Hernane Borges de B. et al. Semantic networks based on titles of scientific papers. Physica A: Statistical Mechanics and its Applications, v. 390, n. 6, p. 1192-1197, 2011. 
${ }^{3} \mathrm{OKOSHI}$, Tetsuro et al. Battery condition monitoring (BCM) technologies about leadacid batteries. Journal of power sources, v. 158, n. 2, p. 874-878, 2006.

${ }^{4}$ ZHANG, Xiaodong et al. Parity-relation-based state-of-health monitoring of lead acid batteries for automotive applications. Control Engineering Practice, v. 19, n. 6, p. 555-563, 2011.

${ }^{5}$ PIŁATOWICZ, Grzegorz et al. Determination of the lead-acid battery's dynamic response using Butler-Volmer equation for advanced battery management systems in automotive applications. Journal of Power Sources, v. 331, p. 348-359, 2016.

${ }^{6}$ BORGES, M. V., MONTEIRO, R. L. S., and PEREIRA, H. B. B.. criar.NET: Software para criar redes no formato Pajek, 2019.

7 BASTIAN, Mathieu; HEYMANN, Sebastien; JACOMY, Mathieu. Gephi: an open source software for exploring and manipulating networks. In: Third international AAAl conference on weblogs and social media. 2009.

${ }^{8}$ WATSON, Christopher G. brainGraph: Graph theory analysis of brain MRI data, R package version 2.7.3. 2019.

${ }^{9}$ ERDÖS, Paul; RÉNYI, Alfréd. On the evolution of random graphs. Publ. Math. Inst. Hung. Acad. Sci, v. 5, n. 1, p. 17-60, 1960. 